An ESRC Research Group

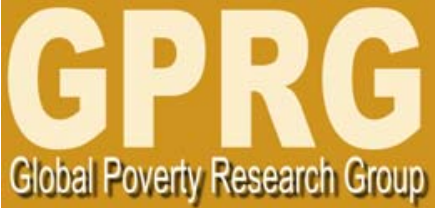

\title{
Rural Poverty: Old Challenges in New Contexts
}

\author{
GPRG-WPS-072
}

\section{Stefan Dercon}

\section{Global Poverty Research Group}

Website: http://www.gprg.org/

The support of the Economic and Social Research Council (ESRC) is gratefully acknowledged. The work was part of the programme of the ESRC Global Poverty Research Group. 


\title{
Rural Poverty: Old Challenges in New Contexts
}

\author{
Stefan Dercon \\ University of Oxford
}

January 2008

\begin{abstract}
Poverty is still a predominantly rural phenomenon. However, the context of rural poverty has been changing across the world, with high growth in some economies and stagnation in others. Furthermore, increased openness in many economies has affected the specific role of agricultural growth for rural poverty reduction. This paper revisits an 'old' question: how does growth and poverty reduction come about if most of the poor live in rural areas, dependent on agriculture? What is the role of agricultural and rural development in this respect? Focusing on sub-Saharan Africa, we use theory and the available evidence to conclude that changing contexts has meant that agricultural growth is only in particular settings crucial as an engine for growth, more specifically in landlocked, resource poor countries, which are often also characterised by relatively low potential for agriculture. However, extensive market failures in key factor markets and likely spatial effects give a remaining crucial role for rural development policies, including focusing on agriculture, to assist the inclusion of the rural poor in growth and development. How to overcome these market failures remains nevertheless a key issue for further research and evaluation.
\end{abstract}

Correspondence to stefan.dercon@economics.ox.ac.uk 


\section{Introduction}

Even though poverty has been coming down in some parts of the world in recent years, not least in East Asia and China, and more recently in South Asia, its persistence in large parts of Africa and elsewhere keeps it high on the agenda. Poverty persistence is to a large extent related to a poor growth performance in national economies. Furthermore, in large parts of the world, poverty also remains in sheer numbers still mainly a rural and agricultural phenomenon, in that most of the poor depend on the rural sector for its livelihood.

This paper will revisit some well-rehearsed but nevertheless relevant questions. What is the place of rural development and agricultural growth in growth and poverty reduction? What are the main rural constraints on growth and poverty? Has more recent economic theory and recent empirical research given more guidance about what can be done? These issues will be discussed keeping in mind some of the poorest parts of the world, most notably sub-Saharan Africa. We will use theory as our guide to structure our discussion, and discuss empirical evidence, even if incomplete, to back up the conclusions.

These questions are well-rehearsed and feature prominently in many general discussions on development. Textbooks typically contain discussions at various level, for example, Ray (1998), or Bardhan and Udry (1999). Longer treatments of these themes can be found in Timmer (2002) or De Janvry et al. (2002). What is different in this paper is that we want to revisit some of the theory and evidence specifically with sub-Saharan Africa in mind; as a result it is highly selective. Overall, the experience with agricultural growth, growth in general, and poverty reduction over the last decades has been disheartening in this region. It has provided the context for renewed calls for a strong focus on agriculture in Africa as a necessary condition for growth and poverty reduction. For example, Sachs has been most vocal in calling for a 'green revolution' in Africa as an essential part of its development strategy (Sachs, 2005). More nuanced analyses, such as the recent World Development Report 2008 on Agriculture for Development, emphasize the crucial role of 
agriculture as being "vital for stimulating growth in other parts of the economy" (p.xiii) in sub-Saharan Africa, requiring strong productivity increases in smallholder agriculture.

This paper will revisit these arguments in the context of the substantial heterogeneity in circumstances and opportunities across sub-Saharan Africa. In the next section, we first briefly summarize the current evidence on the evolution of rural poverty, contrasting the African experience with other parts of the world. The evidence is consistent with a classic view that a move out of agriculture is correlated with overall poverty reduction. In the African context, neither a large scale poverty reduction nor a move out of the rural sector is occurring. Of course, this does not prove a causal link. Nor does it prove that a focus on agricultural growth is not warranted.

In the subsequent sections, we ask how theory as well as the available evidence can inform us on what role agricultural and rural development has to play in both growth and poverty reduction in Africa. In section 3, we offer a discussion of the relevance of a 'macro' view on the role of agriculture in growth and poverty reduction. This will require us to revisit some of the 'old' and seemingly unfashionable questions related to sectoral and urban-rural linkages, to better understand the role of the relevance of agricultural and rural development in the Africa setting. One of the key problems in this review is the relatively sparse evidence, so we rely largely on a simple but suggestive model of ruralurban linkages to make sense of this evidence. Combining this with recent approaches to the question of the scope for growth in Africa, emphasizing its heterogenetiy in opportunities (Ndulu et al., 2008), allows us to identify those specific settings in which agricultural development is likely to be essential in stimulating growth and poverty reduction, as well as the nature and role of rural development in other settings. In particular, it is argued that the role of agriculture is likely to be very different in different settings, depending on whether a country can take advantage of manufacturing opportunities, whether it is natural resource dependent, or whether it is land-locked with few natural resources. It is argued that especially in the latter, a focus on agricultural growth may have to be essential if difficult route out of poverty. 
In section 4, the strong assumptions regarding the nature of markets implied in the macro-view are complemented by a micro-view, emphasizing different market failures, and the possibility of poverty traps. We will focus on three examples of serious market failures, related to credit, risk and spatial effects, reviewing their theoretical impacts and the available evidence. These market failures, especially in circumstances where they may lead to poverty traps, bring rural and agricultural policies back to the fore, leading to suggestive policy conclusions on the role of agriculture and rural development.

\section{Rural Poverty Patterns}

Poverty is still predominantly a rural phenomenon. Pick a random poor person in the world, and the odds are that this person will be living and working in the rural areas as a farmer or agricultural worker. Even though the data are not without problems, the most recent estimates suggest that about 76 percent of the poor in the world live in rural areas, well above the overall population share living in rural areas which is 58 percent (Ravallion et al., 2007). ${ }^{1}$ Sub-Saharan Africa is no exception: while it has the highest poverty rate overall, rural poverty is about a quarter higher than urban poverty, with 65 percent of the population living in rural areas, and 70 percent of the poor are in rural areas. At current patterns of growth, poverty reduction and population growth, poverty is likely to remain a predominantly rural phenomonen for the next few decades (Ravallion et al. 2007).

Is this changing? The figures in Ravallion et al. (2007) also offer a suggestive insight in the recent patterns of urbanization of poverty over the period 1993 to 2002. Even though the urban poverty rate has marginally decreased in the world, the urban share of poverty has been increasing (from about 19 to 24 percent), as the urban population has grown faster than the rural population, largely due to in-migration. ${ }^{2}$ There is considerable variation in this pattern as well. In sub-Saharan Africa, a very marginal decrease in rural

\footnotetext{
${ }^{1}$ This estimate is based on a poverty line of \$1.08 per day in 1993 PPP, applied with a rural-urban correction based on cost-of-living differences between rural and urban areas. Details are in Ravallion et al. (2007).

${ }^{2}$ As the definition of what constitutes an urban area is not standardized across the world's statistical offices, some caution is needed with these statements.
} 
poverty and stagnating urban poverty rates with a growing share of the urban population in the total population, is responsible for a more substantial urbanization of poverty and little change in total poverty. The global overall urbanization of poverty in the context of relatively substantial poverty reduction, and with the larger part of the 'stock' of the poor living in rural areas also implies that rural poverty has contributed most to overall declines in poverty in poverty: using a simple decomposition, Ravallion et al. (2007) calculate that about 80 percent of aggregate poverty declines stem from rural poverty declines. But this obviously does not prove any causality between, say, urbanization and poverty, or indeed that what happens in the rural or agricultural economy is in itself the cause of poverty declines.

In particular, these patterns have to be seen in the broader context of the economy. Growth in GDP per capita and poverty reduction are well known to be coinciding with a gradual decrease of the share of GDP from agriculture as well as the share of the population engaged in agriculture. For example, across all low-income countries, growth stood at about 5 percent per year and the share of agriculture has declined from 32 to 23 percent of GDP between 1990 and 2004 (World Development Indicators, 2005). Contrasting the experience in the 1990s of sub-Saharan Africa with the relatively fast growing regions in East Asia and Pacific (including China), and South Asia, where substantial poverty reduction is taking place, is instructive (table 1). We observe growth of overall GDP far outpacing agricultural GDP growth in both East Asia and South Asia, but not so in sub-Saharan Africa, where overall growth and growth in agricultural GDP were more similar at 2.5 and 3.3 percent per year respectively. ${ }^{3}$ With population growth still at about 2.3 percent per year in sub-Saharan Africa, much higher than in these other regions, per capita growth has been minimal. In other words, there is little sign of a structural transformation in SSA despite signs of some urbanization of poverty, compared to the patterns observed in more successful regions.

\footnotetext{
${ }^{3}$ East Asia includes here the Pacific. Data from the World Development Indicators for 1990-2000 suggest 8.5 percent overall growth in East Asia and the Pacific, and 5.6 percent growth in South Asia, with respectively 3.4 and 3.1 percent growth in agricultural GDP. Growth rates post-2000 are not dissimilar, although overall growth in sub-Saharan Africa appears to have picked somewhat.
} 
For some, agricultural growth is seen as the key engine of growth (Timmer, 2007). The higher recent growth rate in African agriculture is then a sign of hope, even if at current rates they can hardly be viewed as evidence of rapid agricultural transformation. In such a view, the key is to raise agricultural productivity to allow growth to take off. A standard conceptualisation of this process focuses on the existence of linkages in inputs and outputs between agriculture and other sectors (Johnston and Mellor, 1961). Showing sympathy with this view, in the World Development Report 2008, it is argued that in currently agriculture-based economies, high growth in agriculture may well the road to take-off. ${ }^{4}$ Even though the historical evidence on the role of agriculture in allowing the Industrial Revolution to start in Europe is suggestive, and agricultural growth was also significant element in the growth success of East Asia and China, it is much harder to argue that agricultural growth is essential to allow growth to take-off, and the evidence is at best only suggestive.

There is stronger evidence in favour of the view that agricultural growth helps growth to be more pro-poor, albeit possibly dependent on context. For example, in China, it is estimated that growth from agricultural growth contributed up to four times more to poverty reduction, than growth from industry or the service sector (Ravallion and Chen, 2007). However, the rather favourable land distribution may well have played a key role in this, a factor contributing to similar evidence in other East-Asian settings, such as Vietnam. Evidence from India suggests a more subtle message: the impact of the growth in agriculture is matched by growth in services in terms of their poverty-reducing effects, although these poverty-reducing effects from nonfarm growth are larger in states with higher initial farm productivity (Ravallion and Datt, 1996; Ravallion and Datt, 2002). Furthermore, evidence from Foster and Rosenzweig (2004) suggests that areas in India with the slowest growth in agricultural productivity had the largest growth in the rural nonfarm tradable sector.

\footnotetext{
${ }^{4}$ In their analysis, they refer to agricultural-based economies as those with high shares of GDP and labour in agriculture. The geographical composition of this group in their report is such that 82 percent of the subSaharan African rural population is in this group and the share of Africans in the total population of this group is about 90 percent. In short, their analysis and prescriptions for agriculture-based countries are effectively about Africa.
} 
This discussion of patterns and change in rural poverty helps to movitate our further analysis on Africa. It is clear that poverty is highest in rural areas, but is that enough to pay central attention to rural areas and to agriculture? Successful poverty reduction is not simply equated with relatively high growth in agriculture. At best, during periods of rapid poverty reduction correlated with growth, rural growth is likely to be important for poverty reduction, but successful growth is associated with growth in the non-agricultural sector fast outpacing agricultural growth.

In any case, it implies that understanding rural poverty changes cannot naïvely focus only on what happens in the rural sector, or in agriculture. It will have to be done in the context of overall growth and changes, taking into account rural-urban linkages. Arguably, the first systematic treatment of these issues are in the Lewis-model (Lewis, 1954). This model is effectively part of a theory of urban and rural interactions, albeit with particular assumptions about the functioning of markets in urban settings, and especially, the nature of incentives and decision-making. Much work refined this type of analysis further, with a shared underlying research question: how does growth and poverty reduction come about if much activity and labour is initially in the agricultural or rural sector ${ }^{5}$ These questions have somewhat been forgotten in much recent research.

However, the context of the rural sector has also rather dramatically changed in the developing world, say compared to the 1970s and 1980s. In most of the developing world, not least in sub-Saharan Africa, market-based reforms ("getting the prices right") has moved forward dramatically. In Africa, the context of farming and agricultural markets has substantially changed, and virtually everywhere important liberalization, mostly domestic but also increasingly of international trade, has taking place. Globalization and increased openness, as well as investment in commercial agriculture and marketing, are changing the context slowly but in an irreversible way. This provides a different context to ask (again): Can and should agriculture be the engine for growth? Can and should it be an engine for poverty reduction in the context of growth?

\footnotetext{
${ }^{5}$ Further 'classic' treatments are in Ranis and Fei (1964) and Jorgenson (1961).
} 


\section{A role for rural and agricultural growth in growth and poverty reduction in Africa?}

Much basic analysis on the importance of agricultural growth for poverty reduction is based on simplistic premises. For example, it tends to be stated that since the poor are employed in agriculture, agriculture must be the basis of poverty reduction efforts. Against this is one of the basic insights from most data on poverty: that a systematic increase in prosperity tends to be linked to having fewer people dependent on agriculture for their livelihoods. The key question in this respect is - how to get them out of the agricultural sector in a sustainable way?

As it is one of the clearest analyses of this issue, we will build on the work by Eswaran and Kotwal, in a series of academic papers (Eswaran and Kotwal, 1993a, 1993b, 2002) and a monograph, with excellent economic theoretical insights, but with not a single equation in sight (Eswaran and Kotwal, 1994). Its relevance lies mainly in the clarity of the questions asked and answered; most of the points made have obviously been made by others as wel, but rarely as crispy and convincing. In this section, we briefly summarize the key points they make, and give a flavour of the analysis. Their analysis is done with India in mind. In the remainder of this section it will then be discussed how applicable these insights are for other parts of the world, most notably, for Africa.

Eswaran and Kotwal (EW)'s analysis can be thought of as a Lewis model within a proper general equilibrium framework. It also drops some of the most difficult assumptions underlying Lewis' original analysis, but that have remained present in many of the subsequent contributions. To put it bluntly, there is no assumption that rural labour markets work in a way, equivalent to agricultural workers spending too much time sitting under trees (surplus labour that can be freely extracted). Furthermore, industrial workers are not choosing to eat shirts during a critical phase of the growth process (i.e. that when 
total output in agriculture is going down, they are willing to shift to consuming less food and more manufacturing goods). ${ }^{6}$

\section{Theoretical framework}

The EW-model assumes a two-sector economy, industry and agriculture. There are two goods, shirts and food. Production in both sectors is characterized by (different) constant returns to scale production technology using labour, as well as using land in agriculture. There are land owners and workers in the rural economy, and workers in the industrial sector. A crucial assumption is made to make preferences lexicographic: people will first need to have enough food before they will buy shirts. It captures an Engel effect that richer people will spend less on basic essentials, but by making it more extreme, its relevance comes out more directly. An alternative means of looking at this is to state that there is no circumstance in which for very poor people, lower prices for manufactured goods cannot induce to them to cut back on essential basic commodities. Even though in reality it may not be as clear-cut, it takes seriously that poverty is related to deprivation in essential food intake. As EW show, relaxing the assumptions does not fundamentally change the result, but makes the dichotomy in implications under different processes of technological and other development marginally less striking. There is also initial inequality in this economy. Some (the rich) have assets such as land; the poor only have labour. At first, the poor only eat food, since they do not have enough to satisfy their basic needs; once sated with food, they do not eat more. So there is a maximum level of spending on food, and a poor person is someone who only spends on food.

It is further assumed that there are clearing and integrated labour markets across rural and urban areas. ${ }^{7}$ It means that people are indifferent between working in agriculture and

\footnotetext{
${ }^{6}$ For an excellent exposition of the Lewis model, see the textbook by Ray, 1998.

${ }^{7}$ As will be developed further in the next section, this perfect factor markets assumption is crucial and will be challenged in the next section, qualifying some the results in this section. Although offering a rather different model from the one discussed here, Jorgensen (1961) can be seen as a predecessor to the model discussed here, as it also brought in neoclassical market clearing assumptions and issues related to food consumption as a way of characterizing his 'dual economy' model. Ranis and Fei (1964) can be credited with offering some of the general equilibrium analysis presented in EW as well, including the impact of trade, although they used a dual economy setting, rather than competitive factor markets.
} 
industry: contrary to Lewis, these markets are not perfectly segmented, but integrated. Clearing product markets mean that demand equals supply in each. All these assumptions on markets imply that poverty will go down if labour demand increases, increasing real wages. In other words, real wage increases for the initially poor determine whether poverty declines. But how does this work? The set-up can be used to contrast a number of alternative strategies to achieve this. Understanding the context and situation in which these different strategies are effective ways of reducing poverty will also help up to understand how important it is to focus on agricultural and rural development.

First, consider a closed economy, and the policy considered is (neutral) industrial progress via Total Factor Productivity (TFP) growth. Under these assumptions, EW show that this implies that more shirts are being produced for the same amount of labour. Prices for shirts will go down, but crucially: the poor do not care for these cheaper shirts, since they still do not have enough food. The result is that there is no incentive for anyone to move out of agriculture, since total food supply would go down, and demand for food would go up. In the end, the TFP growth only benefits the 'rich' that have enough food and are already consuming shirts: they can consume more. The marginal product of labour in industry goes up, but the price of shirts goes down. Employment is unchanged, and nominal wages, food prices and therefore real wages for the poor are the same as before. Poverty is simply unchanged, despite TFP growth in the industrial sector.

Next, consider again a closed economy and a policy of (neutral) technological progress in agriculture. More food is being produced for the same labour. This is obviously of interest to all the workers: there is more food for the same amount of work. Once there is more food consumed, some may cross the threshold and be sated with food, and become interested in buying shirts. The result is that shirt prices are being pushed up. This creates incentives for firms to expand production, and attract more labour to deliver this increased production. Higher demand for labour will require increasing nominal wages. Rural wages will move up as well, while food prices will go down somewhat since the higher production and the shift to shirts by some previously poor consumers. In 
equilibrium, labour will have moved out of agriculture into shirt production, and higher equilibrium real wages will imply a reduction in poverty.

The contrasting results are striking and lead to the conclusion that in a closed economy, growth in agriculture may well be essential for poverty reduction, while industrial progress has no impact. The presence of demand linkages is the key factor, but for poverty reduction, the relevant linkages are only via commodities consumed by the poor. Mellor and associates have long emphasised this process as well (Mellor, 1999). But there is a difference here: the issue is not just growth linkages but also the link with poverty. Agriculture is then the central engine for poverty reducing growth.

The results are nevertheless strongly affected by the assumptions about openness. In an open economy, the central demand and supply constraints do not matter anymore for traded commodities. Basic food staples can typically be imported, while shirts can be exported. Therefore, assume that both goods are tradable goods, so that only world prices matter.

We can now revisit both cases. First, consider the impact of industrial progress. More shirts are being produced for the same labour input, but prices of shirts remain the same as world prices are not affected. Firms have an incentive to expand production, so the demand for labour and nominal wages will increase. Even though food supply goes down, in this case workers can move since food imports can go up. So the marginal product of labour goes up in agriculture as well, allowing rural and urban wages to increase in nominal and real terms. Food imports with higher real wages will mean that more food is being consumed, and some workers will start consuming shirts. The result is that poverty declines. Secondly, the impact of agricultural technological progress is now very similar to industrial progress. The demand linkages are not crucial anymore for the link between real wages and output, and real wages increase with more people buying shirts than before. 
To put it simply, poverty reduction can then be achieved by any source of increased domestic competitiveness relative to the rest of the world, a fundamentally different resul to the case of a closed economy. It also creates other vulnerabilities: one's trading partner's productivity growth and any loss of relative competitiveness ('dynamic comparative advantage') could have negative implications in terms of poverty (i.e. it has the effects industrial or agricultural decline). Keeping up, or more in general, being able to grow faster in productivity terms than your trading partners is essential. Eswaran and Kotwal, writing near the time of the first moves towards openness in the early 1990s, argue strongly that the evidence is supportive of much potential for India in this respect, especially in growth via technological progress in industry, and that an open trade model could be beneficially assist poverty reduction, even if direct progress in agriculture and the rural sector remained limited. At the same time, technological progress in agriculture has a useful role to play.

Even though the analysis may seem relatively simple, it helps to illustrate some central insights. First, in any scenario, the defining feature of poverty alleviation appears to be linked to the gradual absorption of labour by the non-agricultural sector. There is nothing specific about rural poverty, beyond that it is typically a sign of slow growth. But it goes beyond this: it may also be a sign of the 'wrong' growth forces. Secondly, to understand the role of the agricultural sector in poverty alleviation, it is important to take into account openness. Indeed, the emerging context of globalization changes the dynamic of our understanding of the role of agriculture; it offers more opportunities even though its pitfalls and risks will also need to be properly understood. If the economy is closed, the pattern of growth is crucially important for poverty alleviation. In particular, agricultural growth can then deliver poverty reduction, and given demand linkages, more straightforwardly than industrial progress. Thirdly, introducing more heterogeneity in labour, production technology and sectors does not change the underlying logic - see Eswaran and Kotwal (1993a). However, if technological progress is not 'neutral' or labour intensive, but instead less labour intensive, then the model would predict a far lower impact on the poverty reduction, since labour demand and real wage increases will be more limited. Eswaran and Kotwal (2002) extended the model further with the 
introduction of a service sector and non-tradable goods - the interactions are more subtle but not undermining the main insights.

What does this imply for the importance of agricultural growth? In general, it could play a useful role: in many contexts it may be a most suitable mechanism for poverty reduction. However, one should be careful. Technological progress in agriculture can be thought of as involving the discrete adoption of new inputs, such as new varieties, fertilizer or pesticides. It involves some unpleasant arithmetic: much progress in agriculture itself is a 'once and for all' change. For example, fertiliser adoption may well add about 20 percent higher returns to particular crops, but this is not in itself leading to a persistent year-on-year growth in yields. Any growth effect will largely depend on the presence of very substantial linkages. Some have argued that these linkages are very large in developing countries (e.g. Mellor 1999), although this is largely based on evidence on particular countries using particular methodologies that could be and have been criticized.

The available evidence on India is nevertheless illuminating in this respect, without being conclusive. In a number of papers, Datt and Ravallion $(1998,2002)$ and Ravallion and Datt (1996, 2002), discuss the growth and poverty alleviation experience of India, based on state-level averages, using data until 1994, i.e. largely before the gradual opening of the Indian economy, even though overall growth had picked up during the second half of the 1980s. In other words, India could be thought of as a relatively closed economy. A first key finding from this work is that, based on studying the sectoral composition of growth and poverty, agricultural growth appears to have been able to deliver substantial poverty reduction, while manufacturing growth did not do so in itself. Clearly, this is a result directly predicted by the earlier model. Unpacking this evidence showed that yield increases in agriculture had indeed a strong impact on poverty. Secondly, poverty decreases were strongly influenced by particular (state-specific) 'initial conditions'. One way of interpreting is in terms of linkages: a higher level of a particular characteristic, such as the state of technological progress, delivers ceteris paribus higher year-on-year growth when its impact works itself through the economy in a self-reinforcing way. The evidence suggests that the key initial conditions were higher health and education 
(presumably correlated with underlying productivity of the workers), and better initial conditions in rural areas (including less landlessness and higher initial yields, reflecting better technology). This evidence is clearly consistent with the higher poverty impact from factors increasing the productivity of workers in general, but with a clear role for channelling these growth factors through the rural sector. This is consistent to what was predicted in a closed economy, without necessarily proving that the model is a fully correct representation of the situation.

The opening of the Indian economy and its reasonable success in terms of engaging in the world economy has removed the fundamental demand linkage constraint suggested in the EW model. The sectoral location of productivity growth is becoming less relevant for poverty reduction, provided it is labour-intensive or neutral. The substantial investment in technological progress in other sectors in recent years has opened opportunities for poverty reduction, even though it is likely that the main poverty reducing effects from some of these high-tech service industry investments is likely to have to come from growth linkages towards more low-skill sectors such as construction.

\section{Relevance for Africa?}

Are these results relevant for sub-Saharan Africa? In the Eswaran-Kotwal model, if growth is driven by agricultural growth that is technologically neutral or labour-intensive, then the scope for poverty reduction will be larger. Land is typically not highly unequally distributed in most African countries, with relatively low landlessness and in some countries, such as in Ethiopia, there is a remarkably equal land distrubution. Productivity increases will reward the poorer farmers as well, so that growth may have substantial poverty impacts. The changing circumstances in African agriculture, in terms of allowing many factor and product markets to work more freely, especially in terms of removing much of the urban bias, has improved the opportunities for this process to materialize. A 'green revolution for Africa’ may have then substantial returns.

However, the necessity of agricultural growth to deliver both growth and poverty reduction is not as clear-cut. As in the model, opening up the economy has removed the 
crucial dependence on progress in agriculture to deliver poverty reduction, as the crucial demand linkage with agriculture is removed: growth in other sectors, provided it is labour-intensive, can similarly promote poverty reduction. To assess the case for the crucial role of agricultural growth, the growth opportunities for Africa have to be considered.

Recent work by Ndulu et al. (2008) provides the foundation for a suggestive three-way description of the growth opportunities of sub-African countries; a similar description is used in Collier (2007). They distinguish, in terms of growth opportunities: first, resourcerich economies, secondly, coastal and other well-located countries and finally landlocked economies without natural resources. Each of these groups have very different problems at their core, when trying to boost growth and to reduce poverty.

For resource-rich economies, the key issue is to manage their wealth: how to translate the underlying wealth controlled by the nation into the basis for sustainable and shared prosperity. The key problems they tend to face are Dutch disease and governance problems and are more likely to be ravaged by violent conflict - think Nigeria, Angola or Congo.

For coastal and other well-located countries, the challenge is very different. They have no natural resources, so no immediate source of wealth. It needs to be generated. They have two production factors they can put to good use: they have people and they have their location to their advantage. Much of coastal Africa, not least Ghana, Cote d'Ivoire, Kenya, South or Africa, would spring to mind. Their main challenge is how to take advantage of the opportunities offered by their location. They are countries that in principle should be able to take advantage of world trade opportunities, so their priorities are likely to have to include building up trade infrastructure, managing market institutions and regulation, investing in skills and support the formation of well-working labour markets. These are very different challenges, but globalization offers serious opportunities for them. Without working on their constraints, they are bound to be left behind, but the potential is there. 
This leaves the land-locked, resource poor economies without natural resources. They are suffering most from the agglomeration effects: they have little to offer, and they totally depend on their neighbours to overcome these effects. Matters are made worse if their better located or better endowed neighbours are mishandling their economies, or indeed if they are in conflict with these states. All these factors are creating further negative externalities. Examples are Burundi, Burkina Faso or Ethiopia.

So when is agricultural growth essential? How does agricultural growth then fit in this framework? First, take the resource-rich countries. Agriculture is unlikely to be an essential source of growth. Nevertheless, such an economy needs to find ways of diversifying and building up their productive capacity, and agriculture could play a role in this. In this context, the burden of agricultural growth to drive overall growth is not present, so that efforts for intensification or diversification can have a much more 'propoor' bias. This could involve a focus on smallholder agriculture, for example by supporting new technologies and activities with higher labour productivity. But clearly, there are a variety of ways to encourage the distribution of the wealth of such a country, and it would be hard to argue that stimulating agricultural growth is essential. Moreover, investing in rural areas, including in basic services such as health, education and infrastructure, could be an effective alternative form of redistribution, and may have higher long-term returns in terms of transforming the economy than a narrow focus on agriculture. For example, there would be less burden on ensuring that these investments are largely in high potential areas.

Secondly, consider the well-located economies, who are best placed to take advantage of world economic opportunities. Managing their comparative advantage, via labour markets, skills, regulation and investment climate, is most essential. The role of agriculture is similar to the EW model in an open economy: 'industrial' progress is most likely the best route, and a vehicle to take advantage of trade opportunities. The role of agriculture is then more subsidiary: it makes sense to encourage progress in agriculture as well, if only as a means of managing the pull out of agriculture when trade-based growth 
takes off. ${ }^{8}$ Skill creation via better health and education, also in the rural sector, is then most helpful as well, if only since it will facilitate the development of better skilled labour that can in due course be absorbed. The experience of Indonesia in the late 1970s and 1980s is rather reminiscent of this, with active rural policies, but ultimately leading to more absorption in the urban economy. For African economies, the key challenge is to overcome their relative marginalisation in the world economy, as late-comers are put to a disadvantage in competing with countries that have already an established industrial base, such as many Asian economies. It may require specific support for manufacturing industrial development for this potential to materialize (Collier and Venables, 2007), but it is still the best route for growth.

The landlocked, resource-poor countries are a rather different problem. In many cases think of Ethiopia or Burkina Faso - the agricultural base is at best highly vulnerable. But their risk of total marginalization relative to the world economy is also highest. They are mainly dependent on the ability of their better located neighbours to pull them into tradeoriented opportunities, often involving migrant labour. In terms of active policies, the opportunities are limited: infrastructure and skill creation are sensible, but as locations for investment are likely to remain down the pecking order for a long time, not least with many better located neighbours still only barely integrating with the world economy at present. As a consequence, the best way to think of these economies is as if they are effectively closed economies, irrespective of active trade liberalization. As the model predicted, agricultural growth is then essential for both growth and poverty reduction but don’t expect any miracles. Technological progress in agriculture has to be actively pursued, as well as other measures to raise rural productivities as the main way of delivering growth that also has clear poverty reducing impacts. Rural and agricultural development is likely to be hardest here, as they are often agriculturally more vulnerable areas, but it is here where it has to be attempted with most vigour. In order to achieve poverty reduction, there are also likely to be important trade-offs between stimulating

\footnotetext{
${ }^{8}$ Of course, high-value agricultural activities, such as flowers, fruits or vegetables in Kenya, are also effective means to take advantage of locational and other advantages. Air transport is a (possibly increasingly) expensive means of transporting exports, making location sufficiently near to ports a continuing necessity for a trade-oriented growth model, and not a straightforward option, say, for landlocked countries Ethiopia.
} 
agriculture in the high potential areas (as likely to be required for growth) with promoting it in more marginal areas, where poverty may be highest.

The contrast between, say, Ethiopia, and India is striking here. Ethiopia may have been trying to open up in recent years, but with neighbours that are better located but not taking advantage of trade opportunities and in general, with whom relations are at best frosty (such as in Somalia or Eritrea). This limits its options dramatically. At best it can create basic infrastructure, create skills but growth is likely to have to come via agriculture to encourage any systematic and persistent decline in rural poverty. Its population cannot take advantage of growth opportunities in neighbouring countries to trade or even migrate. India has surely pockets and even states that face similar local natural resource constraints and other problems to Ethiopia (e.g. Bihar). But its economy is broadly integrated and with some states taking advantage of its increased openness and location, growth externalities and employment opportunities provide options for these lagging states to at least take partial advantage of the overall change, with some beneficial impacts on local poverty reduction.

\section{Market Failures and Poverty Traps?}

The previous section has focused on a macro or general equilibrium narrative on the role of agricultural and rural development in growth and poverty reduction. Changing contexts, not least the increased openness of developing countries and the move towards more market-based economies changes the role of agriculture and rural development in

growth and poverty reduction, not least because urban-rural and sectoral interactions have to be properly integrated in the analysis. However, this preceding analysis is conducted using the assumption of well-functioning factor and product markets. As much of the rural development research in recent decades has highlighted, market failures are prevalent, even despite the removal of many policy-induced market imperfections, such 
as in agricultural product markets. ${ }^{9}$ Resources are then not allocated efficiently, until marginal returns to different factors of production are equalised. Factor markets, including for labour, serve different people differently, resulting in heterogeneity in the extent to which people with different initial circumstances can take advantage of opportunities, including those offered by growth. Rural non-market institutions may have developed to partially substitute or compensate for market failures, but not completely. This has important implications, not just for the extent of growth that can be achieved, but most importantly for our purposes, the extent the poor can partake in growth. While the underlying taxonomy of general growth opportunities in different parts of subSaharan Africa developed in the previous section is unlikely to be fundamentally affected, the ability of these growth narratives to deliver poverty reduction and broad inclusion in the growth process definitely is.

In this section, we try to put some of the key lessons from the extensive micro-level research on rural households and institutions from the last few decades in the broader context of poverty reduction and growth. The key question is: what do we know about the key constraints of the rural poor to participate in or contribute to growth? Much of the recent academic literature on rural issues has explored many of these market failures in factor markets, such as land, labour, credit and insurance. This typically forms the core of much of the teaching offered in graduate schools in the microeconomics of development. ${ }^{10}$ However, the key issue for our purposes is to explore how micro-level issues can be put into the bigger picture of growth and poverty reduction.

In the remainder, we will consider the question of what would cause some poor people to remain locked in rural poverty, even if countries that manage to start growth processes, intensive in terms of labour. Furthermore, for countries that are absolutely dependent on rural development efforts for poverty reduction via growth, such as land-locked resource poor countries with 'poor' neighbours, the need to unlock rural potential means that we should especially carefully examine what may cause growth in particular rural areas to

\footnotetext{
${ }^{9}$ This type of research is carefully discussed in detail in Bardhan and Udry (1999), Mookherjee and Ray (2001).

${ }^{10}$ Ray (1998) provides an excellent entry point to this literature.
} 
stay behind. We will focus on three instances that illustrate a more general principle and finding in recent theoretical work, with much suggestive empirical evidence: "initial poverty and market failures conspire to keep some poor people persistently poor or even in a poverty trap.” I will focus on three problems linked to market failures which may induce these processes: access to capital (credit market failure); risk (insurance market failure) and spatial externalities (curse of geography).

\section{Credit market failure and poverty traps}

The most obviously observable market failure is the failure of credit markets to conform to the assumptions of perfectly competitive markets. Under perfect and complete markets, anyone with a profitable project should be able to get a loan at the current interest rate. If markets were perfect and efficient, no bank would ask for collateral to secure the loan. ${ }^{11}$ In practice, without collateral, one typically would not get the loan. Collateral requirements can be understood as an important means by which credit markets handle the central problems that bedevil these markets: asymmetric information, such as moral hazard and adverse selection, and enforcement problems. Since imperfect information means that borrowers may not be able to know which projects are more risky among many risky projects, or whether lenders will implement other actions than initially committed to after the loans have been granted, collateral may be asked for to secure the loans. Collateral may also help to enforce the repayment of loans.

Starting from initial asset poverty for some, it is obvious that this may be a market failure that is particularly hurtful for the poor, by excluding them from profitable opportunities. A number of careful, suggestive models, most notably Eswaran and Kotwal (1986), show its key implications: the rich do not just earn more income because they have more assets, but also they can use assets more efficiently. Market failures force some of the poor to be inefficient, and they exacerbate any initial inequality - some of the poor may stay behind.

\footnotetext{
${ }^{11}$ In this discussion, we use the issue of collateral as a heuristic device to show the differential impact on the poor of credit market failures, without arguing that this is necessarily the key failure. Most other failures in credit markets can be shown to result in a specific disadvantage for poorer households. A useful discussion of different market failures in rural credit markets (and what to do about it) is in Besley (1994) or in Ray (1998).
} 
There is much suggestive evidence that similar processes are common in agricultural settings, often linked to credit market failures. A key prediction of this model is that the marginal return to bringing more land into production by the poor outweighs that of the rich, and that average output per hectare is larger for the poor than for the rich. This negative correlation between cultivated land area and output per hectare is commonly observed in developing countries. Binswanger et al. (1995) provide a comprehensive overview of the evidence and look into different explanations. Land quality heterogeneity is certainly part of the story, but factor market failures, including related to credit, are likely to be relevant as well.

The model described is effectively a static model - but its potential dynamic implications are intuitively appealing. Starting from some inequality in assets, those with more wealth earn higher returns and plausibly can accumulate at a high rate while the poor enter into technology or activity portfolios with lower returns, and may not be able to start accumulating any wealth. This intuition is at the basis of a number of growth models leading to poverty traps for some and accumulation for others. Banerjee and Newman (1993) show the adverse impact of asset inequality on growth, linked to credit market failures. When threshold levels of assets are needed to enter into different activities, then entry into profitable activities is closed off for those with limited assets, and they are trapped in poverty, while others can climb the occupational ladder. A poverty trap is an equilibrium outcome and a situation from which one cannot emerge without outside help, for example, via a positive windfall to this group, such as by redistribution or aid, or via a fundamental change in the functioning of markets. Much other work suggests poverty traps and overall efficiency and growth losses due to poverty and inequality combined with credit market failure, where some people are unable to exploit growth-promoting opportunities for investment (e.g. Galor and Zeira, 1993; Aghion and Bolton, 1997; Benabou, 1996). This credit market failure model is also a central part of the narrative underlying the 2006 World Development Report (World Bank, 2005); it discusses also some suggestive evidence of its implications. 
If credit market induced poverty traps are present in rural areas, or more in general, underinvestment is present, limiting growth. Furthermore, if growth picks up but if access to profitable opportunities requires some minimal investment (e.g. being able to invest in the migration of some household members or sunk costs for a newly profitable activities), then credit market failures may result in the exclusion of some of the poor from the benefits from growth. Proving the existence of credit-induced poverty traps is difficult, but there is definitely evidence in rural Africa of entry costs in particular activities and assets in the presence of limited access to investment capital, leading to poorer households holding less profitable portfolios (Barrett et al. 2005; Dercon, 1998).

What to do about them is less clear. Credit market interventions have long been a favoured intervention, in recent times mainly via microfinance schemes, although other interventions may well be better and more useful to resolve credit market failures, see Besley (1994). It is also not altogether clear that the poorest are benefiting most from microfinance (Amendatriz de Aghion and Morduch, 2005) and more needs to be learned from careful evaluations of specific products that could have the highest impact (Karlan and Goldberger, 2006). For Africa, the key question is also whether microcredit is not overrated as a means to fostering inclusion of the rural poor in the economy: often, if applied to rural settings, it is seen as a means of helping to get the rural poor into off-farm business activities, usually with restrictions on the eligible activities via the support offered by the microfinance institution. Even though credit market restrictions may exclude them from certain profitable opportunities, it is unlikely to be the case that large scale poverty reduction is going to be achieved by making more and more people dependent on enterpreneurial activities. In most economies, the transformation towards a higher income and low poverty economy has been achieved by an increase in wageemployment, via higher labour demand, with farmers become employees in industry and the service sector. It is likely that in the long-run, the highest returns are to be obtained from health, education and skills, not least in Africa economies that are resource-rich or whose potential is in manufacturing exports. Of course, the transition is likely to be helped by allowing some people to take advantage of enterpreneurial opportunities in agriculture and the nonfarm sector, but it is unlikely to be a large-scale succesful route. 
There is a dilemma here as well: as long as growth is not taking off, the poor are likely to be helped more by encouraging enterpreneurial activities, as labour demand is not picking up. In most African contexts, returns to education are convex: low for primary and possibly high for higher levels of education (e.g. Söderbom et al. 2006), so that investing in education under circumstances of the 1980s and 1990s, with low wagelabour demand, is unlikely to offer rapid routes out of poverty, but if growth were to pick up in a sustained way, this could change. Failing that, microcredit schemes could offer a solution for many poor, but without growth it is not offering real scope for large-scale poverty reduction. In any case, and at best, microcredit schemes with more flexibility, that do not try to tie people to particular enterpreneurial activities, but that respond to the general financing needs of families, may be more effective (Karlan and Mullainathan, 2007).

\section{Insurance market failures and risk induced poverty traps}

Another serious market failure impacting disproportionately on the poor is the lack of insurance and protection of the poor in the face of risk. Complete insurance markets (or, to be technically more accurate, complete state-contingent markets) is another assumption for perfect markets that tends to be violated in practice. Problems with asymmetric information and enforcement issues, not dissimilar to those causing credit market failures, are again typically responsible for the limited spread of insurance mechanisms in developing countries. Even if they wanted to, the poor could not get any insurance for most of the risks they face.

Uninsured risk causes considerable hardship to the poor. Developing countries are still characterised by a high incidence of natural disasters, drought, conflict and insecurity, as well as economic shocks, such as commodity price shocks and currency shocks. Health problems are widespread, as are pests in agriculture. It is commonplace to view these problems as 'transitory' problems, requiring temporary solution, such as some form of safety net, after which one should get back to the bigger issues of development. For the 
policy maker it also often means that it is just a social issue that should not distract the key (macroeconomic) policy makers from the bigger issue of how to stimulate growth in the economy and widespread poverty. However, this is misleading. There is increasing evidence that risk and shocks are a cause of lower growth, especially resulting in lower growth of incomes of the poor and possibly poverty traps. Focusing attention on the poor could then again be contributing to both growth and equity; in any case, it could be instrumental to ensuring that the poor can benefit from emerging growth.

Households in developing countries have developed sophisticated mechanisms to cope with risk. Typically, one could consider two types of responses: risk-management strategies and risk-coping strategies. Risk management strategies involve trying to shape the risks they face by entering into activity portfolios that are more favourable in terms of risks. For example, entering into low risk activities or diversifying into portfolios of activities with differing risk profiles - growing more drought resistant crops, entering in petty trading or firewood collection, seasonal migration, etc. Risk coping strategies involve activities to cope with consequences of risk in income. Two types are commonly observed: self-insurance using savings, often in the form of cattle or small ruminants, to be sold off when the need arises, and informal mutual support mechanisms, where members of group or community provide transfers to each other in times of need of one of its members, typically on a reciprocal basis (Fafchamps, 1992).

These strategies are not without cost: income risk management strategies result in a reduction in mean income to have face risk and variability in income, while adjusting asset portfolios to cope with risk typically involves investing in liquid assets with lower returns rather than in productive illiquid investment. This affects their long-term income and their ability to move out of poverty. Indeed, there is growing evidence that these strategies imply substantial efficiency loss for the poor, which the rich - typically better protected via insurance, asset and credit - do not have to endure (a review is in Dercon, 2002). Morduch (1995) documents how more profitable technologies are not adopted because they are too risky in a particular setting in India. The same farmers have been found to hold livestock as a precaution against risk even when more productive 
investment opportunities exist (Rosenzweig and Wolpin, 1993). Rosenzweig and Binswanger (1993) found that the loss in efficiency between the richest and poorest quintiles in their sample from India was more than 25 percent, attributable to portfolio adjustments in assets and activities due to risk exposure. In Ethiopia, Dercon and Christiaensen (2007) have found that modern input adoption is lowered due to the downside risk related to input loans, whose repayment is strictly enforced, even when rains and harvests fail. Over time, this results in substantial efficiency losses, affecting the poor disproportionately.

These risk management strategies may trap the poor in poverty: to avoid further destitution, they are forced to forgo profitable but risky opportunities, and with it the opportunity to move out of poverty ${ }^{12}$. Even so, they cannot fully protect themselves: there is much evidence that although the strategies contribute to less variability in consumption and nutritional levels, they are still not able to cope with some serious, repeated shocks, not least those affecting whole communities, regions or countries (Morduch, 1999; Dercon, 2002). These uninsured shocks typically wipe out assets, pushing the households down the asset distribution. They could be pushed below some critical threshold, trapping them into poverty from then on, for example due to the risk strategies they then need to follow to avoid further destitution, or due to other processes.

There is growing evidence that these processes are an important cause of poverty persistence and possibly permanent traps in developing countries. Jalan and Ravallion (2003) investigated the presence of poverty traps using data from China, and although they did not find a pure poverty trap, they found that households took several years to recover from a single income shocks, and that the recovery was much slower for the poor. There is also related evidence from Africa. Dercon (2004), using panel data from rural Ethiopia, found signs of poverty persistence linked to uninsured shocks, with the impact of rainfall up to 4 years ago affecting current growth rates, and the extent to which households had suffered in the famine of 1984-85 still contributing to explain growth rates in the 1990s. Furthermore, it took on average ten years for livestock holdings, a key

${ }^{12}$ See Banerjee (2003) for a formal poverty trap model building on this idea. 
form of savings in rural Ethiopia, to recover to the levels seen before the 1984-85 famine. In a careful study, Elbers et al. (2007), use simulation based econometric methods to calibrate a growth model that explicitly accounts for risk and risk responses, applied to panel data from rural Zimbabwe. They found that risk substantially reduces growth, reducing the capital stock (in the steady state) by more than 40 percent. Two-thirds of this loss is due to ex-ante strategies by which households try to minimize the impact of risk. Barrett (2005) has suggestive evidence on poverty traps by looking at livestock holdings of pastoralists in Kenya.

There is also increasing evidence on the long-term implications of uninsured shocks, focusing on health and education. For example, the permanent impact of drought on children is well documented - lower adult height, poor education outcomes and therefore lower lifetime earnings. For example, the impact of drought and war in rural Zimbabwe in the early 1980s on a particularly vulnerable cohort of children was estimated at 7-12 percent of lifetime earnings or more (on this and other evidence, see Dercon and Hoddinott, 2003).

All this evidence points to the important consequences of lack of insurance and protection in rural settings in developing countries, particularly affecting the poor. Given that the root cause is again a market failure, exacerbated by poverty, there is a clear case for interventions that are potentially both poverty reducing as stimulating efficiency and growth; in any case, they could ensure that the poor can more effectively take part in growth processes. In developed countries, not least in Europe, the failings of the insurance markets are largely resolved via some form of universal social insurance and substantial direct means-tested transfers. For developing countries, this is not likely to be cost-effective, involving high administrative costs and high informational requirements. To put it simply, the means for such systems are unlikely to be available.

Many responses can be considered, from reducing the risks faced by rural households (e.g. by preventative health services, or better water management for agriculture), strenthening of existing responses (such as investing in better savings product provision, 
or better functioning assets markets, such as for live animals) and improved forms of insurance and broader social protection in the form of safety nets. While each have their problems and advantages, in recent years a number of specifically interesting initiatives have been taken with respect to insurance, even if their benefits are not quite substantiated yet. ${ }^{13}$

\section{Spatial effects}

Another common cause for market failure is the presence of spatial externalities.

Externalities are said to be present if economic or other interactions create social gains or costs beyond those taken into account by those involved in the interaction. The standard example is environmental damage from production involving pollution not accounted for by the buyers and sellers of the commodity produced. A more general phenomenon in developing countries, that can be best understood in terms of externalities, involves geographically defined areas that appear to stay behind - poor neighbourhoods, or even poor regions or countries. If one looks at the performance of the developing world, it has been striking over recent decades that some developing countries - largely in Africa appear to have become increasingly marginalised, with low economic growth, persistent population growth and generally, persistent poverty. Less studied but at least as important is that even in countries were growth is high, there appear to be areas that systematically stay behind and do not benefit from the overall economic growth in terms of income growth and poverty reduction. Certain regions in China and India may well fit this bill. Much less documented but no less true, the geographical disparity in growth and poverty reduction performance within African countries is similarly present. ${ }^{14}$

Such disparity may well be explained in terms of theories emphasising agglomeration or location effects, predicting that firms will exploit increasing returns resulting from the presence of externalities to locating in the same geographical areas, implying that firms

\footnotetext{
${ }^{13}$ For a helpful review of targeted transfers and safety nets, see Ravallion, 2003. For a review on a broad set of means of offering on 'insurance' to the poor, see Dercon (2003) and the contributions therein. Of particular interest are initiatives to offer rainfall insurance, including in Africa, even initial evaluations result in surprising results (Gine and Yang, 2007).

${ }^{14}$ For a review, see Kanbur and Venables (2005). Lack of convergence between rural and urban areas in a number of wealth indicators across 12 African countries is found in Sahn and Stifel (2003).
} 
would locate in clusters (Fujita et al. 1999). The corollary is that some less attractive locations may have missed the boat: not only would they not get the required investment, any capital present may well move out to capture the higher returns elsewhere. For those areas that missed the boat, there is a negative externality from the success of other areas. Clearly, this is a form of a poverty trap: although initially these areas may not have been very different, once they missed the boat, they can only escape by a serious exogenous shock or massive effort. They face a substantial threshold that they need to overcome to attract or retain capital for accumulation.

Other explanations similarly emphasize externalities related to the specific local context, for example low local endowments in terms of public goods, common property resources and private asset holdings. If growth processes require a certain threshold of local endowments to take off, then poorly endowed areas may well find it hard to escape poverty. Proving this is difficult. There is some evidence for China and a few other countries. ${ }^{15}$ For Africa, the role and effects of remoteness on growth and poverty in Africa are well discussed in Christiaensen et al. (2005), with evidence from a number of countries.

Recall that these externalities are again market failures that specifically affect those at the lower end of the asset distribution - this time with assets broadly defined to include public and environmental goods. Given that poverty traps are identified, this empirical evidence would justify 'poor areas' programmes - massive investment programmes in particular deprived areas to build up locational and community capital. However, these empirical studies lack sufficient detail and a clear narrative about how these externalities come about. More evidence would be needed to guide and prioritize the type of interventions that would be most beneficial.

\footnotetext{
${ }^{15}$ Jalan and Ravallion (2002) identify geographic poverty traps in rural China during the 1980s, finding that community characteristics affect the income growth performance of otherwise identical individuals, controlling for latent heterogeneity. There results showed that in some areas living standards were falling while elsewhere otherwise identical households were enjoying rising living standards, an effect entirely due to externalities from the initial community characteristics.
} 
For example, most rural 'poor areas' typically are characterised by remoteness - often linked to the lack of roads and communications infrastructure. One of the most common donor policy responses is to build roads into poor areas. While undoubtedly bringing some benefits to remote communities, it is not necessarily the case that this is what is needed to unlock the growth potential of an area. In some countries, there is evidence that this may well be an appropriate response ${ }^{16}$ Still, historically much road building in developing countries has been in response to local economic growth or at least in recognition of some growth potential (such as cash crops or mining), and it was not the main cause of growth. Alternatives, such as irrigation, health or educational schemes may be more important to unlock their potential.

In any case, just doing a little is not going to help - in order for such areas to catch up, substantial levels of investment would be needed to lift them over the threshold. It may well be the case that creating opportunities to leave may be a superior policy. Migration nevertheless also involves costs, so this may be difficult too. If these thresholds are substantial, then growth opportunities elsewhere may simply bypass many rural poor. But it is nevertheless the prime example of a potential rural poverty trap for which solutions have to be firmly considered in the context of rural-urban and other linkages, and a narrow focus on rural areas may be ineffective.

\section{Conclusions}

Contrary to most of the rest of the developing world, poverty levels have remained stagnant in sub-Saharan Africa in the last few decades, in a context of slow growth. As most of the poor are living in rural areas, it may lead to the conclusion that agricultural growth and rural development policies have to be at the core of growth and poverty reduction policies.

\footnotetext{
${ }^{16}$ Ravallion and Jalan (2002) present evidence for China that roads are relevant for growth. Microdata from Ethiopia using a much smaller sample suggest similar effects i.e. growth effects from levels of infrastructure (Dercon, 2004).
} 
In this paper, we used a 'macro' (intersectoral) and micro-perspective to discuss some of the key concerns and issues involved in an African context. Using a framework based on Eswaran and Kotwal (1993b), and evidence on growth opportunities in Africa based on Ndulu et al. (2008), we concluded that agricultural growth is likely to be essential for landlocked and resource-poor economies in Africa, even though growth opportunities via agriculture are likely to be difficult. In others, in particular those with good location for engagement into manufacturing exports, or resource-rich economies, agriculture is not the crucial constraint. Even if rural development policies are likely to be crucial to allow the gradual transformation of the economy, the pressure for agricultural growth to be an engine of growth is not present.

This analysis is however based on well-functioning factor and product markets, allowing specifically the poor to take advantage of opportunities irrespective of their endowments. Perfect markets in rural settings are not the appropriate assumption. There is considerable evidence that this implies that poor may remain excluded of profitable opportunities to grow out of poverty, even if growth has picked up in the economy, potentially leading to poverty traps. Rural development policies targeted on the poor, and possible including stimulating agricultural production by poor farmers may then be part of effort to make growth more inclusive. The mechanisms by which this exclusion may happen are well understood, and we discussed credit and insurance market failures, as well as spatial effects, in the form of 'poor areas'. The evidence on the appropriate responses is still only emerging, and clearly more experimentation and research is needed.

\section{References}

Aghion, P. and P.Bolton, (1997), "A Trickle-Down Theory of Growth and Development with Debt Overhand”, Review of Economic Studies, 64, 2: 151-62.

Armendariz de Aghion, B. and J.Morduch (2005), The Economics of Microfinance, Cambridge (MA): MIT Press.

Banerjee, A. and A. Newman (1993), 'Occupational Choice and the Process of Development’, Journal of Political Economy, 101, 2: 274-98. 
Banerjee, A. (2003), “The Two Poverties”, chapter in S. Dercon (ed.), Insurance against Poverty, Oxford: Oxford University Press.

Bardhan, P. and C.Udry (1999), Development Microeconomics, Oxford: Oxford University Press.

Barrett, C., (2005), "Rural Poverty Dynamics: Development Policy Implications”, Agricultural Economics, 32(1): 45-60.

Barrett, C.B. M.Bezuneh, D.C.Clay, and T.Reardon, (2005), "Heterogeneous Constraints, Incentives and Income Diversification Strategies in Rural Africa," Quarterly Journal of International Agriculture, 44 (1): 37-60.

Besley, T. (1994), "How do market failures justify intervention in rural credit markets?”, World Bank Research Observer, 9(1): 27-47.

Bénabou, R. (1996), “Inequality and Growth”, in B.Bernanke and J.Rotemberg (eds), National Bureau of Economic Research Macroeconomics Annual, Cambridge: MIT Press, pp.11-74.

Binswanger, H., K.Deininger and G.Feder, (1995), "Power, Distortions, Revolt and Reform in Agricultural and Land Relations", in J.Behrman and T.N.Srinivasan (eds.) Handbook of Development Economics, volume 3, Amsterdam: NorthHolland.

Christiaensen, L., L.Demery and S.Paternostro (2005), "Reforms, remoteness and risk in Africa: Understanding Inequality and Poverty During the 1990s." in R.Kanbur and A.J.Venables (eds.), Spatial Inequality and Development. Oxford: Oxford University Press.

Collier, P. (2007), The Bottom Billion, Why the Poorest Countries are Failing and What Can Be Done About It, New York: Oxford University Press.

Collier, Paul and Venables, Anthony J., "Rethinking Trade Preferences: How Africa Can Diversify its Exports" . The World Economy, 30 (8):1326-1345.

Datt, G. and M.Ravallion, (2002), "Is India's Economic Growth Leaving the Poor Behind?” Journal of Economic Perspectives, 16(3), 89-108.

Datt, G. and M.Ravallion, (1998), "Why Have Some Indian States Done Better Than Others at Reducing Rural Poverty?” Economica, 65 (257), pp.17-38.

De Janvry, A., E. Sadoulet and R. Murgai (2002), "Rural Development and Rural Policy”, Chapter 31 in Handbook of Agricultural Economics, vol. 2 A, pp. 15931658. 
Dercon, S. (1998), "Wealth, risk and activity choice: cattle in Western Tanzania", Journal of Development Economics, 55 (1): 1-42.

Dercon, S. (2002), 'Income Risk, Coping Strategies and Safety Nets', World Bank Research Observer, vol. 17, 141-166.

Dercon, S. (2004) "Growth and Shocks: evidence from Rural Ethiopia", Journal of Development Economics, August, vol 74 (2), pp. 309-29

Dercon, S. (2003), Insurance against Poverty, Oxford: Oxford University Press and WIDER.

Dercon, S. and L.Christiaensen (2007), “Consumption Risk, Technology Adoption and Poverty Traps: Evidence from Ethiopia”, World Bank Policy Research Working Paper no. 4257.

Dercon, S. and J. Hoddinott (2003), "Health, Shocks and Poverty Persistence”, chapter 6 in S. Dercon (ed.), Insurance against Poverty, Oxford: Oxford University Press.

Elbers, C., J.W.Gunning and B.Kinsey (2003), 'Growth and Risk: Methodology and Micro Evidence’,. The World Bank Economic Review, 21(1): 1-20.

Eswaran, M. and A. Kotwal (1986), “Access to Capital and Agrarian Production Organisation”, Economic Journal, 96: 482-98.

Eswaran, M. and A.Kotwal (1993a), "Export Led Development: Primary vs. Industrial Exports”, Journal of Development Economics, July, 163-172.

Eswaran, M. and A.Kotwal (1993b), “A Theory of Real Wage Growth in LDC’s”, Journal of Development Economics, December, 243-269.

Eswaran, M. and A.Kotwal, (1994) Why Poverty Persists in India, Oxford University Press, New Delhi.

Eswaran, M. and A.Kotwal (2002), "The Role of Service Sector in the Process of Industrialization", Journal of Development Economics, (68), 401-420.

Fafchamps, M. (1992), "Solidarity Networks in Preindustrial Societies: Rational Peasants with a Moral Economy," Economic Development and Cultural Change 41(October): 147-74.

Foster, A. and M.D.Rosenzweig, (2004), “Agricultural Productivity Growth, Rural Economic Diversity, and Economic Reforms: India, 1970-2000” Economic Development and Cultural Change, 52(3): 509-42. 
Fujita, M. asahisa, Paul Krugman, and Anthony Venables (1999) The Spatial Economy: Cities, Regions, and International Trade, Cambridge: MIT Press

Gine, X. and D.Yang, (2007), "Insurance, Credit, and Technology Adoption: Field Experimental Evidence from Malawi" World Bank Policy Research Working Paper No. 4425.

Jalan, J. and M. Ravallion (2002), “Geographic Poverty Traps? A Micro Model of Consumption Growth in Rural China”, Journal of Applied Econometrics, 17: 329346.

Jalan, J. and M. Ravallion (2003), "Household Income Dynamics in Rural China", chapter 5 in S. Dercon (ed.), Insurance against Poverty, Oxford: Oxford University Press.

Johnston, B.F., and J.W. Mellor. (1961) "The Role of Agriculture in Economic Development." American Economic Review, 51 (4):566-93

Jorgenson, D. W. (1961), "The Development of a Dual Economy," Economic Journal, 71(282): 309-334.

Galor, O. and J. Zeira (1993), 'Income Distribution and Macroeconomics', Review of Economic Studies, 60: 35-52.

Kanbur R. and A.J.Venables (eds.), (2005), Spatial Inequality and Development. Oxford: Oxford University Press.

Karlan D. and N. Goldberg (2006), "The Impact of Microfinance: A Review of Methodological Issues”, mimeo Poverty Action Lab and Yale University.

Karlan, D. and S. Mullainathan (2007), “Is Microfinance Too Rigid”, mimeo Poverty Action and Yale University.

Lewis, A.W. (1954), "Economic Development with Unlimited Supplies of Labor", Manchester School, 139-91.

Mellor, J. (1999), "Faster, More Equitable Growth - The Relation between Growth in Agriculture and Poverty Reduction”, Agricultural Policy Development Project Research Report no 4, Abt Associates Inc Cambridge MA.

Mookherjee, D. and D.Ray (2001), Readings in the Theory of Economic Development, Oxford: Blackwells Publishing.

Morduch, J. (1995), 'Income Smoothing and Consumption Smoothing', Journal of Economic Perspectives, Vol.9 (Summer), 103-14. 
Morduch, J. (1999), 'Between the State and the Market: Can Informal Insurance Patch the Safety Net?’, World Bank Research Observer, Vol.14, No.2 (August), 187207.

Ndulu, B.J., S.A. O’Connell, R.H. Bates, P.Collier and C.C. Soludo (eds.), (2008), The Political Economy of Economic Growth in Africa, 1960-2000, Cambridge University Press.

Ranis, G and J.C.H.Fei, (1964), Development of the Surplus Economy: Theory and Policy, Homewood Illinois: R.D.Irwin for the Economic Growth Center Yale University.

Ravallion, M. (2003), 'Targeted Transfers in Poor Countries: Revisiting the Trade-Offs and Policy Options’, World Bank Policy Research Working Paper No. 3048.

Ravallion, M. and G.Datt (1996), “How important to India’s poor is the sectoral composition of economic growth”, World Bank Economic Review, 10, January: 126.

Ravallion, M. and G. Datt, (2002) "Why has economic growth been more pro-poor in some states of India than others”, Journal of Development Economics, 68 (2002): 381-400.

Ravallion, M., S. Chen and P.Sangraula (2007), "New Evidence on the Urbanization of Global Poverty”, World Bank Policy Research Paper No.4199.

Ravallion, M. and S.Chen (2007). "China's (Uneven) Progress Against Poverty." Journal of Development Economics 82(1):1-42.

Ray, D. (1998), Development Economics, Princeton: Princeton University Press.

Rosenzweig, M. and H. Binswanger (1993), 'Wealth, Weather Risk and the Composition and Profitability of Agricultural Investments’, Economic Journal, 103: 56-78.

Rosenzweig, M. and K. Wolpin (1993), 'Credit Market Constraints, Consumption Smoothing, and the Accumulation of Durable Production Assets in Low-income Countries: Investment in Bullocks in India', Journal of Political Economy, 101,(2): 223-44.

Sachs, J. (2005), The End of Poverty: Economic Possibilities for Our Time Penguin Press.

Sahn, D. and D.Stifel (2003), "Urban-Rural Inequality in Living Standards in Africa”, Journal of African Economies 12(1): 564-97. 
M.Söderbom, F.Teal, A.Wambugu, G.Kahyarara, (2006), “The Dynamics of Returns to Education in Kenyan and Tanzanian Manufacturing”, Oxford Bulletin of Economics and Statistics, 68 (3), pp. 261-288.

Timmer, P.C. (2002), “Agriculture and Economic Development” in B.Gardner and G.Rausser (eds.), Handbook of Agricultural Economics, Volume 2A, North Holland.

Timmer, P. C. (2007), “Agriculture and Economic Growth”, in D.A.Clark (ed.) The Elgar Companion to Development Studies, Cheltenham: Edward Elgar.

World Bank, (2005), World Development Report 2006: Equity and Development, Oxford University Press for the World Bank.

World Bank (2007), World Development Report 2008: Agriculture for Development, Oxford University Press for the World Bank.

World Bank, (2005), World Development Indicators, Oxford University Press for the World Bank. 